J. Lake Sci. (湖泊科学), 2011, 23(1): 112-121

http: //www.jlakes.org. E-mail: jlakes@niglas.ac.cn

(c) 2011 by Journal of Lake Sciences

\title{
长江上游地区可利用降水量的气候特征”
}

\author{
郭 渠 ${ }^{1}$, 程炳岩 ${ }^{1}$, 孙卫国 ${ }^{2}$, 李 瑞 $^{3}$ \\ ( 1 : 重庆市气候中心, 重庆 401147) \\ (2: 南京信息工程大学应用气象学院, 南京 210044) \\ (3: 济南市气象局, 济南 250002)
}

摘 要: 利用长江上游地区 107 个观测站 1960-2008 年气温、降水观测资料,采用陆面蒸发经验模型计算得到各观测站 的月蒸发量, 再根据水量平衡关系, 得到可利用降水量, 采用数理统计、REOF 分析和 M-K 突变检验等方法, 分析长江上游 地区可利用降水量的气候变化特征. 结果表明: 长江上游可利用降水量季节变化显著, 5-9 月长江上游可利用降水出现 2-3 个高值中心且中心位置稳定少变, 10-4 月可利用降水基本上呈由南向北逐渐减少的特征. 长江上游夏半年可利用 降水的空间分布类型可分为长江上游东南区、东北区、中部区、西北区、北部区和西南区. 大气降水在可利用降水量中起 决定性作用. 当夏季西太平洋副热带高压偏北偏西 (偏南偏东) 时, 长江上游东部地区可利用降水量偏少 (多); 当东亚 (南亚) 夏季季风偏强(弱)时,长江上游东部(西北部) 可利用降水量偏少(多).

关键词: 可利用降水量; 气候特征;旋转主成分分析; 长江上游地区

\section{Climatic features of utilizable precipitation in the upper Yangtze River}

\author{
GUO Qu ${ }^{1}$, CHENG Bingyan ${ }^{1}$, SUN Weiguo ${ }^{2} \&$ LI Rui ${ }^{3}$ \\ (1:Chongqing Climate Center, Chongqing 401147, P. R. China) \\ (2:Department of Applied Meteorology, Nanjing University of Information Science and Technology, Nanjing 210044, P. R. \\ China) \\ (3: Jinan Meteorological Bureau, Jinan 250002, P. R. China)
}

\begin{abstract}
Based on the observational temperature and precipitation data of 107 stations in the upper Yangtze River basin during $1960-2008$, the utilizable precipitation was calculated by Takahashi's evaporation equation and the relationship of water balance. The climatic characteristics of utilizable precipitation in the upper Yangtze River basin were studied by means of mathematical statistics, the analysis of REOF and M-K methods. The results showed that the seasonal variation of utilizable precipitation was obvious in the upper Yangtze River basin. The utilizable precipitation in the upper Yangtze River basin from May to September appeared two or three centers and the centers little moved. From October to April, the utilizable precipitation showed a gradual decrease from south to north. The analysis of REOF showed that the spatial distribution of the utilizable precipitation in the upper Yangtze River basin were abnormal in several types: southeast, northeast, middle part, northwest, north and southwest in summer half year. Precipitation played a crucial role in the utilizable precipitation. When the West Pacific Subtropical High( WPSH) shifted northward and westward( southward and eastward) in summer, the utilizable precipitation in the eastern part of upper Yangtze River basin was less(more). The utilizable precipitation in the eastern(northwestern) upper Yangtze River basin was less(more) while the East( South) Asian summer monsoon was stronger(weaker).
\end{abstract}

Keywords: utilizable precipitation; Cimatic feature; rotated principal component analysis; upper Yangtze River

近年来, 全球气候变化对水资源的影响已成为世界科学界所关注的重要问题 ${ }^{[1]}$.气候变化及其对水资

* 重庆市气象局重点业务建设项目 “气候变化对三峡库区水资源的影响评估研究” 和南京信息工程大学科研基金项 目 (9922) 联合资助. 2009-11-23 收稿;2010-06-17 收修改稿. 郭渠, 男,1978 年生, 硕士, 工程师; E-mail: guoqu510@163.com. 
源的影响已引起国内学者和有关部门的高度重视 ${ }^{[2-13]}$. 叶笃正等 ${ }^{[2]}$ 研究认为, 中国过去 50 年来气候带北移, 产生相应的季节响应. 陈华 ${ }^{[3]}$ 和郝振纯 ${ }^{[4]}$ 等研究了气候变化对汉江和黄河源区水资源的影响, 表明黄河源 区蒸发能力对气温的增加非常敏感, 不仅能够抵消降水的可能增加, 还将在一定程度上造成水资源量的减 少. 长江是中国的第一大河,流域内众多大中小城市组成的经济带、资源带和产业带,对我国社会经济的可 持续发展起着举足轻重的作用. 长江上游地形复杂, 既受东南季风和西南季风影响, 又受青藏高原的影响, 是气候变化的脆弱地区 ${ }^{[12]}$. 然而在全球变暖的气候背景下, 长江上游地区表现出不同的区域响应特征, 这将 会对区域环境生态产生巨大的影响 ${ }^{[13]}$. 总体而言, 长江上游地区是一个水资源变率较大的地区, 某些年份出 现异常丰水,可能引发洪涝等灾害,而某些年份则出现异常枯水,可能出现旱灾及人畜饮水困难. 可见,水资 源的任何异常变化都会对经济发展乃至社会各方面带来影响. 可利用降水量是大气降水资源各分量中 (降 水量、蒸发量和可利用降水量) 可被人们实际利用的降水资源. 关于长江流域的水资源变化,特别是长江流 域降水已有一些研究 ${ }^{[5-11]}$, 得到许多有价值的结果. 而专门分析长江上游地区可利用降水资源及气候因子异 常对长江上游可利用降水资源变化影响的研究还不多见. 因此, 深人研究长江上游地区水资源变化, 特别是 可利用降水量变化特征,对于更好地理解气候变暖的区域响应过程;对于指导长江上游地区湿地的保护和 规划管理、长江流域未来水资源的规划、开发利用不仅具有重要的学术价值,而且具有重要的现实意义.

\section{1 研究区域及资料与方法}

研究区域为长江上游地区, 位于 $90^{\circ}-115^{\circ} \mathrm{E}, 25^{\circ}-36^{\circ} \mathrm{N}$ 之间, 地处欧亚大陆副热带东部. 地理位置确定 了其鲜明的东亚副热带气候特征,温暖湿润. 该区域地形复杂,气温、降水空间、时间分布的变化较大.

长江上游流域的选站原则是: 沿流域干支流 分布均匀, 选取尽可能多的站点, 测站具有一定代 表性.资料由中国气象局国家气象信息中心气象 资料室提供,资料包括长江上游流域 227 个台站 $1951-2008$ 年的逐日降水量和平均气温资料. 为 了减少资料的非均一性, 在资料选取时规定: 月内 逐日资料缺测达 $5 \mathrm{~d}$ 的, 该月资料定为缺测 ; 1 年 中有 1 个月缺测时, 该年年值为缺测; 然后参考 Easterling 等 ${ }^{[14]}$ 的方法, 对各站资料进行 $t$ 检验, 剔除超出显著水平 0.01 的站点. 长江上游流域共 有 227 个台站, 本文剔除了不满足上述条件的 120 个站点资料,最后选用分布于长江上游流域 107 个气象站 (图 1) 的逐日气温和降水数据, 所

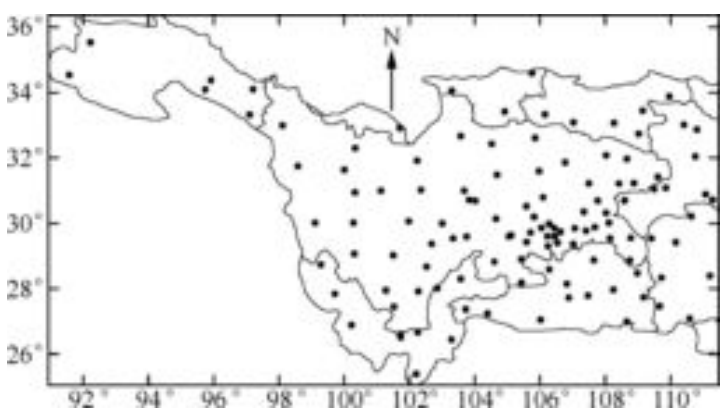

图 1 长江上游地区站点分布

Fig. 1 The location of the observatory stations in the upper Yangtze River 用数据时段为 1960 年 1 月 1 日至 2008 年 12 月 31 日.

蒸发量的观测在大气科学中至今还是一个难题, 目前常规气象站观测的蒸发量实际上是水面蒸发, 由 于实际蒸发受种种条件限制, 如气象条件、土壤性质及地表植被等,所以蒸发血观测的蒸发量对实际蒸发量 的代表性并不好. 为此人们研究了许多经验估算方法, 如彭曼公式、彭曼一蒙蒂斯公式等在理论上考虑影响 蒸散发能力的要素比较全面, 但由于资料要求高而在应用中受到一定限制. 实际情况下, 影响蒸发的最主要 物理因子是降水和温度,同时考虑到气象资料收集的难易程度,采用高桥浩一郎的经验公式来计算蒸 发量 ${ }^{[15]}$.

$$
E=\frac{3100 P}{3100+1.8 P^{2} \exp \left[\frac{34.4 T}{235+T}\right]}
$$

式中, $E$ 为月蒸发量 $(\mathrm{mm}), P$ 和 $T$ 分别为月降水量 $(\mathrm{mm})$ 和月平均气温 $\left({ }^{\circ} \mathrm{C}\right)$. 根据水量平衡关系:

$$
H=P-E
$$


式中表示用月降水量减去月蒸发量,即可得到可利用降水量 $(H, \mathrm{~mm})$.

该公式方法简便,特别是克服了在低温下无法计算和陆面蒸发会大于降水的缺点; 在物理上考虑影响 实际蒸发的最主要的两个物理因子, 并且有实际观测资料作依据, 作为经验公式, 其广泛性已经被很多学者 证实并且广泛应用. 陶云等 ${ }^{[16]}$ 曾验证了该公式在云南地区的适用性, 周长艳等 ${ }^{[17]}$ 在分析高原东侧川渝盆地 降水与水资源特征及变化、李林等 ${ }^{[18]}$ 在分析 “三江源” 地区气候变化趋势及其突变时也采用该公式计算陆 面蒸发量, 取得较好的应用效果. 在以上确定了月可利用降水量的基础上, 本文统计出长江上游地区 107 个 气象站 $1960-2008$ 年各站逐月可利用降水量并建立了时间序列, 然后运用 EOF、REOF ${ }^{[19]}$ 、趋势分析 ${ }^{[20]}$ 、 Mann-Kendall 突变检验 ${ }^{[21]}$ 等方法对该时间序列进行了时空分布特征分析.

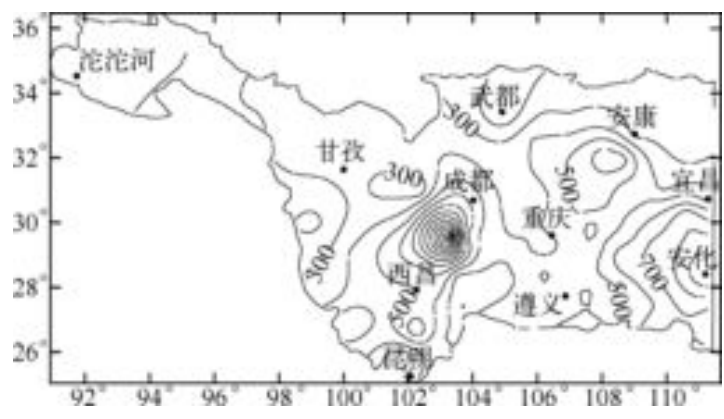

图 2 长江上游地区年平均可利用降水量分布

Fig. 2 Distribution of annual utilizable precipitation in the upper Yangtze River

\section{2 结果分析}

\section{1 长江上游可利用降水空间分布}

$1960-2008$ 年长江上游年平均可利用降水量 分布表明,长江上游可利用降水量空间分布很不 均匀,呈现南多北少、盆地及其东部多和川西高原 少的特征(图 2). 南北部的年平均可利用降水量 相差 $110 \mathrm{~mm}$ 左右, 而东部和长江源地区的年平均 可利用降水量差异更大, 达到 $560 \mathrm{~mm}$ 左右. 可利 用降水量最大值出现在四川的雅安一带, 年平均 可利用降水量达 $1000-1500 \mathrm{~mm}$, 其次为湖南的安 化、通道一带, 年平均可利用降水量为 $750-$ $1000 \mathrm{~mm}$. 云、贵高原北部为 $200-600 \mathrm{~mm}$, 川、渝地

区 (不含川西高原) 和湖南、湖北北部地区为 $300-700 \mathrm{~mm}$. 陕西、甘肃南部为 $180-320 \mathrm{~mm}$, 属于长江上游可 利用降水的次低值区; 川西高原 (包括青海长江源地区) 年平均可利用降水量为 $130-320 \mathrm{~mm}$, 为最低值区; 最小值出现在长江源头的沱沱河、五道梁, 年平均可利用降水仅为 $136.69 \mathrm{~mm} 、 144.45 \mathrm{~mm}$. 这种可利用降水 分布形式与长江上游特殊的地形地貌、降水和气温的空间分布有关. 长江上游地区主要位于青藏高原东部, 高山、平原、丘陵相间, 北部、西北部的高山峻岭阻挡了南下的天气系统, 因而影响长江上游的天气系统主要 从南部、东部进人, 天气系统在北移西进过程中, 在迎风坡的抬升作用和局地对流的影响下, 容易产生降水, 可利用降水量增多. 杜川利等 ${ }^{[22]}$ 利用 NCAR 公用陆面模式 CLM3 计算的中国区域年平均水资源分布 (降水 减去地面蒸发和植被蒸散) 在长江上游地区的数值与本文接近, 说明高桥浩一郎方法计算蒸发量在长江上 游地区是适用的.

\section{2 长江上游可利用降水量的年内变化}

近 49 年来长江上游地区各月平均可利用降水量可见, 长江上游可利用降水量 7 月最大, 其次是 6 月、 8 月、 5 月和 9 月, 12 月最小 (图 3). 长江上游可利用降水量主要集中在夏半年 (5-9 月), 占全年的 $78.34 \%$;

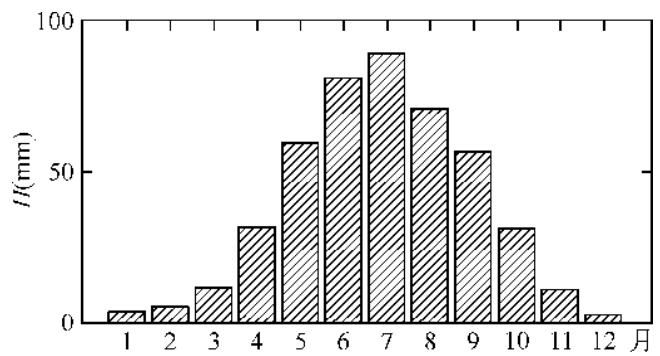

图 3 长江上游月平均可利用降水量

Fig. 3 Monthly utilizable precipitation in the upper Yangtze River
夏季主要受西南季风及东亚副热带高压边缘暖湿气流 的共同影响, 可利用降水量较多, 达 $240.34 \mathrm{~mm}$, 占全年 的 $52.80 \%$; 冬半年 $(10-4$ 月) 西风带主要受高原地形 影响出现南北两支气流, 两支气流都比较干, 造成冬季 可利用降水量少, 3 个月可利用降水量只有 $12.43 \mathrm{~mm}$, 仅占全年的 $3 \%$; 春、秋季降水相对较少, 分别占全年可 利用降水量的 $22.73 \%$ 和 $21.73 \%$.

不同月份长江上游可利用降水量的区域分布特征 也不相同,存在着明显的季节性差异. 1 月 (图 4a), 可 利用降水量主要分布在 $30^{\circ} \mathrm{N}$ 以南, $102^{\circ} \mathrm{E}$ 以东的安化、 武冈、邵阳、通道、吉首、芷江等地; 最大值为 $46.61 \mathrm{~mm}$, 
位于湖南的安化. 2 月 (图略) 可利用降水量有所增加但幅度不大, 可利用降水量带轴线明显北移, 中心值介 于安化、邵阳一带. 3 月、4 月 (图 4b) 变化基本相同,长江上游可利用降水量明显增多，中心位置维持不变， 4 月中心值分别增大为 3 月份的 1.61 倍 $(101.08 \mathrm{~mm})$ 和 2.58 倍 $(161.63 \mathrm{~mm})$ ，同时还出现四川雅安一带的 次高值中心. 5 月变化与 4 月基本相同, 川西高原增长幅度较大, 尤其是长江源地区的五道梁、沱沱河分别增 大为 4 月份的 10.88 倍 $(7.48 \mathrm{~mm})$ 和 16.30 倍 $(4.34 \mathrm{~mm})$, 大值中心位置维持不变. 6 月 (图略)可利用降水量 中心移至四川的峨眉、九龙一带, 中心值增至 $189.96 \mathrm{~mm}$, 湖南的安化、桑植一带, 可利用降水量达 $145-165 \mathrm{~mm}$ ，属于次高值区; 长江上游可利用降水量呈现以 $29^{\circ} \mathrm{N}$ 向南北线性减少的特征, 北部的商州至武 都一带为可利用降水最少区,为 $11-20 \mathrm{~mm} .7$ 月 (图 4c) 长江上游可利用降水量大值区移到西南部, 中心位 置少动, 仍在四川的峨眉一带, 强度较 5 月显著增长, 中心值为 $349.01 \mathrm{~mm}$; 川西高原至长江源地区增至全年 的最大值, 为 $50-120 \mathrm{~mm} .8$ 月 (图略) 中心值强度基本相等且位置保持不变, 峨眉、雅安为全年最大值, 分别 为 $416.90 \mathrm{~mm} 、 354.39 \mathrm{~mm}$; 其余各地可利用降水量变化幅度较小,在 $40-120 \mathrm{~mm}$ 之间. 9 月 (图略) 长江上游 可利用降水量东南部减少, 北部显著增加, 同时还出现东北部的次高值中心; 除西南部外, 呈北多南少的特 征. 10 月 (图 4d) 长江上游可利用降水量减少, 四川峨眉、雅安一带高值中心消失, 中心向东偏移; 同时出 现东南、东北两个高值中心, 分别是重庆的城口、西阳, 为 $69.10 \mathrm{~mm} 、 62.63 \mathrm{~mm}$; 川西高原可利用降水量是减 少的大值区,平均只有 9 月的七分之一. 11、12 月 (图略) 长江上游可利用降水量迅速减少, 东北高值中心消 失,东南中心向南偏移.川西高原可利用降水量降至 $1 \mathrm{~mm}$ 以下.
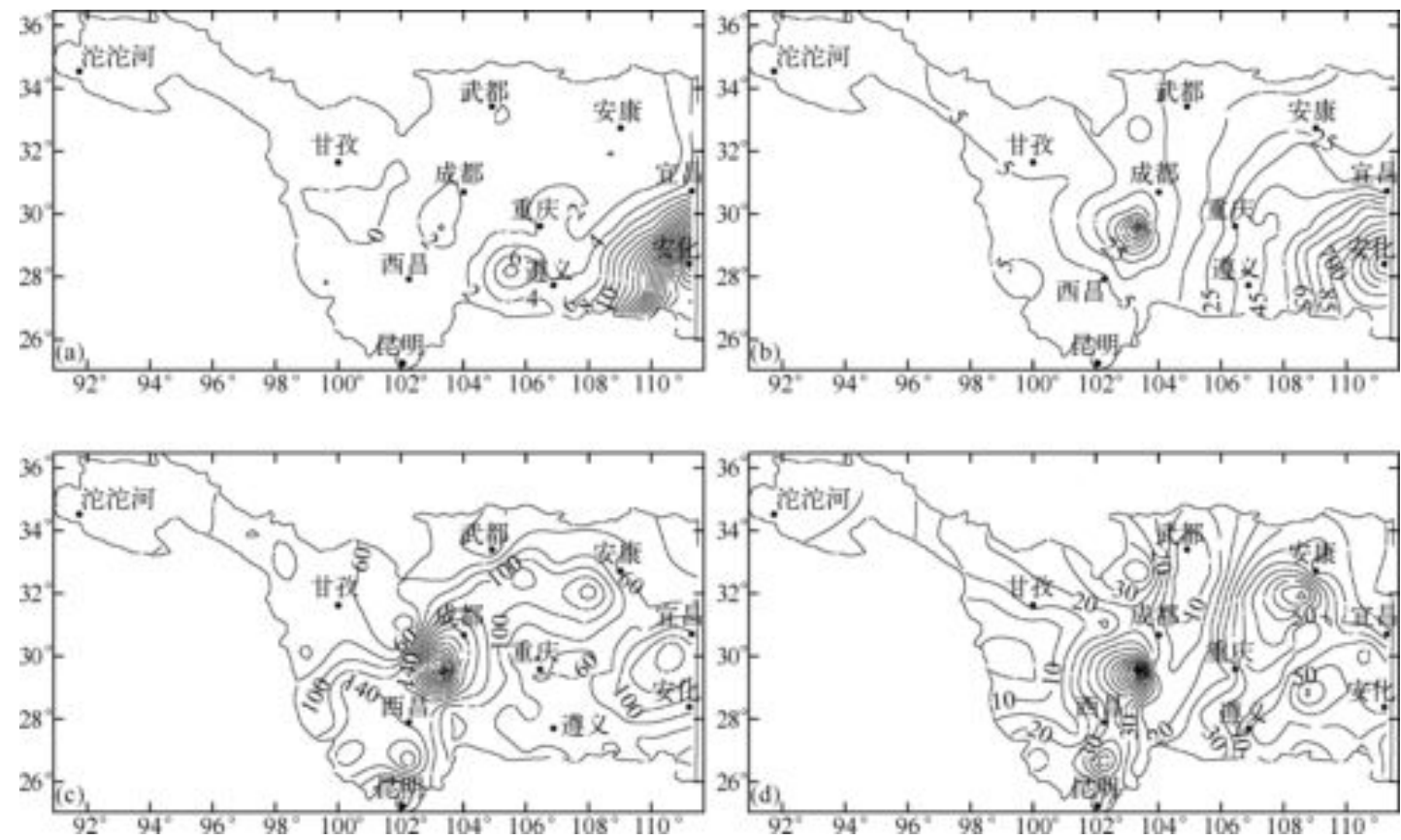

图 4 四季代表月可利用降水量的分布:(a)1 月,(b)4 月,(c)7 月,(d)10月

Fig. 4 The distributions of monthly utilizable precipitation in the upper Yangtze River:

(a) January, (b) April, (c) July and (d) October

由逐月可利用降水量大值中心的变化动态可知: 由冬至夏可利用降水量逐月增多,8 月份达到最大 值,其中川西高原在 7 月达到最大,夏半年 5-9 月均出现 2-3 个可利用降水量大值中心, 分别位于中部 的四川峨眉、雅安一带,东北的重庆城口一带,东南的湖南安化一带. 四川峨眉、雅安一带可利用降水量大 值中心稳定少动. 由夏至冬可利用降水量逐月减少, 尤其 10 月份以后, 可利用降水量骤减, 其中以 12 月 
为最少. 冬半年 10-4 月可利用降水量大值区域在东南部, 可利用降水量基本呈现由东南向西北逐渐减 少的特征.

\section{3 长江上游可利用降水量的空间分布异常特征}

由上述分析已知, 可利用降水量季节变化比较明显, 其中夏半年可利用降水量占全年的 $78.34 \%$, 所以, 分析夏半年长江上游可利用降水量的空间分布异常特征具有实际意义. 为突出可利用降水量异常的分布类 型及其与年际变化的联系, 这里采用区域内各观测站夏半年 (5-9月) 可利用降水量的距平值. 旋转前后前 十个模态对总方差的贡献可以看出, 随着时间尺度的扩展, 其收玫速度明显降低, 在一定程度上反映了该地 区地形极其复杂,局地可利用降水量的时空特征差异较大 (表 1). 为保证 EOF 分解的可靠性,用 North 等 ${ }^{[23]}$ 提出的计算特征值误差范围的方法进行显著性检验, 经计算前 6 个 EOF 旋转载荷向量满足要求, 能够较好 地反映夏半年长江上游可利用降水量的空间异常特征. 如图 5(a-f) 所示, 阴影区表示旋转载荷向量绝对值 大于 0.5 的区域.

表 1 长江上游地区可利用降水量 EOF 和 REOF 分析各分量的方差贡献率(\%)

Tab. 1 The variance contribution rates of the principal components of EOF and REOF analyses of utilizable precipitation in the upper Yangtze River

\begin{tabular}{cccccccccccc}
\hline 序号 & 1 & 2 & 3 & 4 & 5 & 6 & 7 & 8 & 9 & 10 & 累积贡献率 \\
\hline EOF & 24.21 & 11.38 & 7.95 & 6.50 & 4.85 & 3.90 & 3.89 & 3.52 & 2.98 & 2.55 & 71.73 \\
REOF & 21.63 & 12.17 & 8.51 & 6.74 & 5.18 & 4.18 & 3.95 & 3.55 & 3.14 & 2.68 & 71.73 \\
\hline
\end{tabular}

I 区: 是长江上游东南部型 (图 5a), 旋转载荷向量高值区集中在遵义、桐梓至西阳、秀山一带,高值中心 在泊潭地区 $(+0.76)$, 纬度位置偏南, 夏半年主要受东亚与南亚季风影响, 基本属于亚热带季节性湿润气 候区.

II 区: 长江上游东北部型 (图 5b), 旋转载荷向量高值区集中在巴中、城口至安康、汉中一带, 高值中心 在万源地区 $(+0.84)$, 纬度位置偏北, 夏半年主要受东亚季风影响, 盛夏主要被西太平洋副高所控制, 基本 属于亚热带湿润气候区.

III 区: 长江上游中部型 (图 5c), 旋转载荷向量高值区集中在南充、遂宁至铜梁、沙坪坝一带, 高值中心在 大足地区 $(+0.94)$,夏半年主要受东亚季风影响,基本属于中亚热带湿润季风气候区.

IV 区: 长江上游西北部型 (图 5d), 旋转载荷向量高值区集中在囊谦、康定、甘孜一带, 高值中心在新龙 地区 $(+0.87)$; 该地区地势较高且地形复杂, 夏半年主要受高原热力、动力作用以及西南季风的共同影响, 基本属于高原型大陆与亚热带交杂的气候区.

$\mathrm{V}$ 区: 长江上游北部型 (图 5e), 旋转载荷向量高值区集中在峨眉、广元至武都、略阳一带, 高值中心在都 江堰地区 $(-0.79)$, 夏半年主要受南亚季风和高原动力、热力作用的共同影响, 同时又位于西太平洋副高西 部边缘, 降水多,基本属于亚热带湿润季风气候区.

VI区: 长江上游西南山地型 (图 5f), 旋转载荷向量高值区集中在西昌、会理、元谋一带, 高值中心在昭觉 地区 $(+0.73)$, 该地区是川西南山地干热河谷地区, 属于川西高原与四川盆地的过渡地带, 位于四川盆地西 南端, 地理位置特殊,地形复杂, 属于亚热带高原季风气候区.

以上述各分区的旋转荷载值中心为基点, 求它与周围台站可利用降水量距平间的相关系数 (图略), 结果显示, 在各分区内可利用降水量序列异常相关明显 $(r>0.51)$, 分区外则反之. 这进一步说明上述分 区符合可利用降水量异常分布实际, 能够反映可利用降水量异常的主要空间分布类型. 这样, 按 图 5(a-f) 中各旋转荷载值等值线 (绝对值 $>0.5$ ) 的范围, 并参考地理区域, 客观地确定了长江上游可利 用降水量异常的六个主要空间分区, 基本概括出长江上游可利用降水量的东西向和南北向异常的主要分 布特征, 按照各自方差贡献由大到小的顺序, 它们分别是长江上游东南区、东北区、中部区、西北区、北部 区、西南区. 

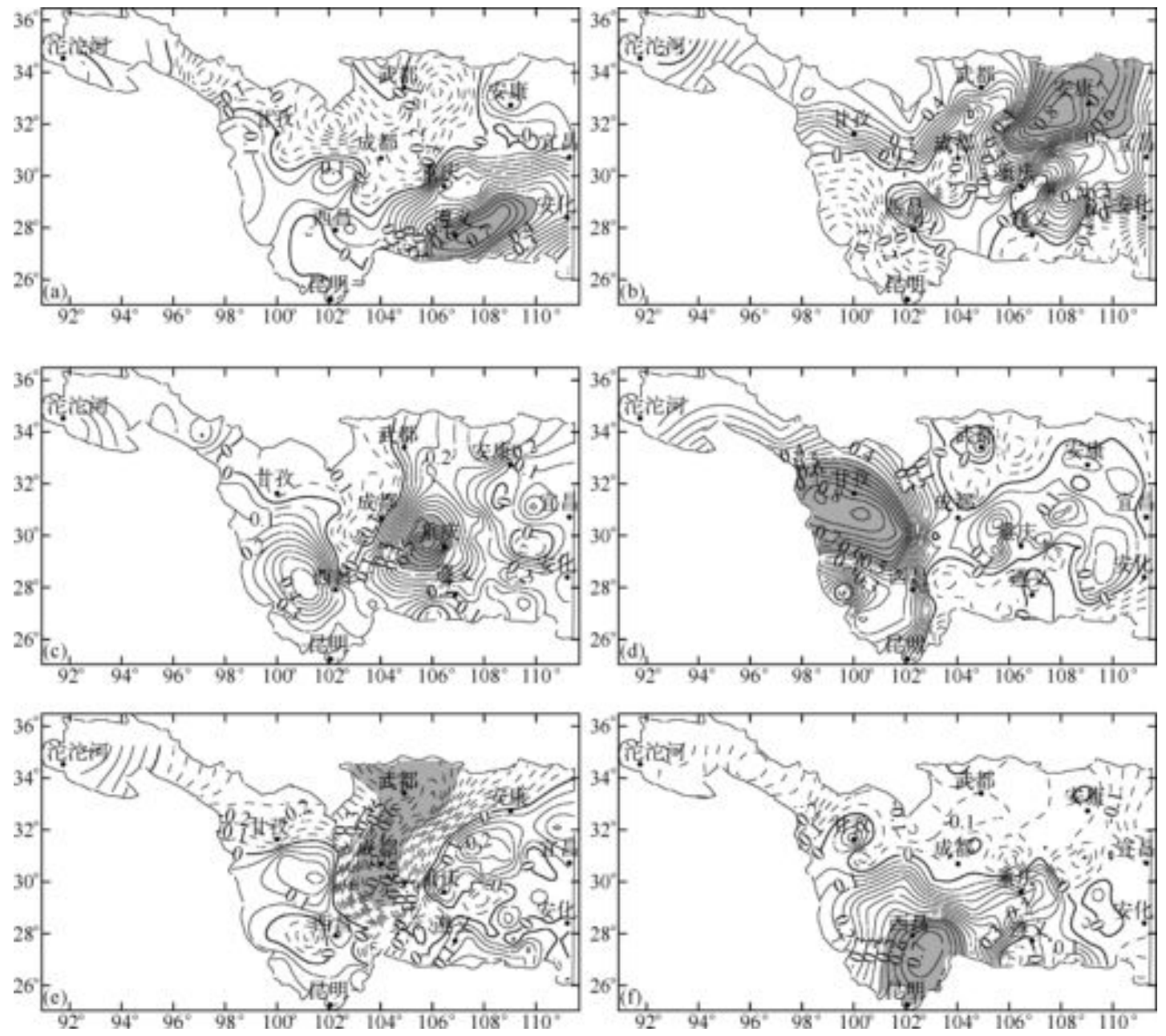

图 5 REOF 前 6 个主要模态 (阴影范围对应荷载向量绝对值大于 0.5 的高值区)

Fig. 5 Spatial distribution of the first six main REOF modes

( shading represents the absolute value of load vector more than 0.5 )

\section{4 长江上游可利用降水量的趋势变化}

从年可利用降水量的倾向率空间分布 (图 6) 来看,各地可利用降水量的空间分布很不均 匀,其空间变化以 $103^{\circ} \mathrm{E}$ 呈现西部增多东部减少 的变化趋势; 西部主要减少区域为四川的木里一 带,而东部增加区域为合川、沙坪坝、大竹一带, 幅度都较小. 增长率大于 $1 \mathrm{~mm} / \mathrm{a}$ 的区域主要位 于川西高原, 增长最明显的为四川的康定和西 昌, 增长率分别为 $2.30 \mathrm{~mm} / \mathrm{a} 、 2.15 \mathrm{~mm} / \mathrm{a}$; 减少最 明显的为四川的都江堰、乐山, 减少率分别为 $6.04 \mathrm{~mm} / \mathrm{a} 、 5.92 \mathrm{~mm} / \mathrm{a}$.

用各代表站夏半年可利用降水量时间序列进 行 Mann-Kendall 突变检验. 图 7 为新龙站夏半年

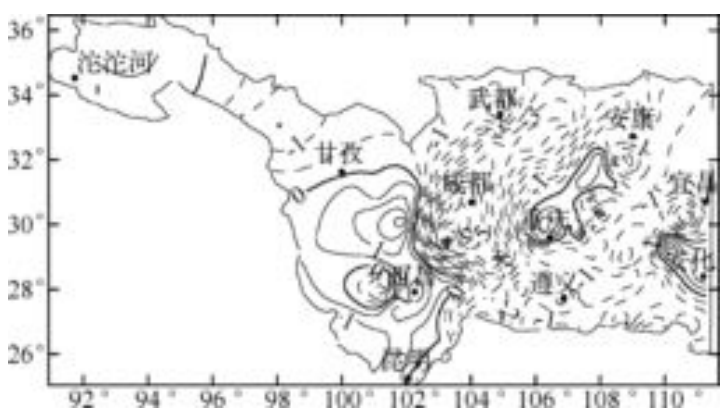

图 6 年可利用降水量倾向率的空间分布 (单位: $1 \mathrm{~mm} / \mathrm{a}$ )

Fig. 6 Tendency rate spatial distribution of annual utilizable precipitation in the upper Yangtze River 


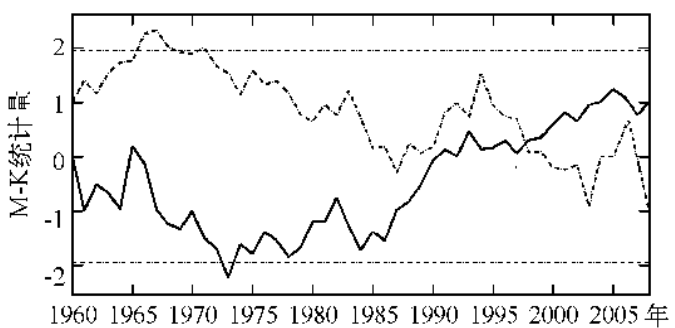

图 7 新龙站夏半年可利用降水量的 M-K 突变检验

Fig. 7 The M-K test of utilizable precipitation in summer half year in Xinlong Station
可利用降水量的 M-K 检验曲线,其他代表站图略. 6 个代表站中只有 IV 区代表站新龙在 1997 年发生过 一次突变, 夏半年可利用降水量有明显的增加 趋势.

\section{5 长江上游地区可利用降水量与气温、降水的} 关系

IPCC 第 4 次评估报告指出,自 1861 年以来,全 球表面年平均温度不断上升,近 100 年来的上升幅 度为 $0.74 \pm 0.18^{\circ} \mathrm{C}^{[24]}$. 中国近百年的温度变化趋 势与北半球大致相似 ${ }^{[25]}$, 其中 $1956-2005$ 年间温 度升高了 $1.25^{\circ} \mathrm{C}^{[24]}$, 这种温度的上升趋势还在持 续, 气候变暖加剧对水资源的影响也不可忽视. 为了分析长江上游地区可利用降水量与气温、降水的关系, 计算了各区蒸发量、可利用降水量和它们之间的相关系数, 结果表明除西南部山区外, 蒸发量、可利用降水 量与降水量的变化基本一致 (表 2), 降水量在可利用降水量中起决定性作用 (表 3). 假设在气温不变的情 况下, 当降水量增多 (或减少) 时, 虽然蒸发量也增多 (或减少), 但由于降水量基数的加大 (或变小), 可利 用降水量还是随之增多 (或减少). 但如果降水量很大时, 可能因空气易于饱和, 蒸发量反而减少 ${ }^{[25]}$. 气温 与可利用降水量呈负相关, 除西南部、西北部区外, 均通过了 0.01 置信度检验 (表 2). 东北部区在 70 年代 和 90 年代、西北部区在 60 年代和 90 年代降水量都较为接近, 由于 90 年代气温分别高于两区的 70 年代 与 60 年代, 导致东北部区与西北部区 90 年代的蒸发量分别大于 70 年代和 60 年代 (表 3), 而两者的可利 用降水量相差无几, 由此可见, 虽然降水量是可利用降水量的决定性因素, 但由于气温变化所造成的影响 也不可忽视.

表 2 夏半年气温、降水与蒸发、可利用降水量之间的相关系数

Tab. 2 Correlation coefficients between temperature, precipitation and evaporation, utilizable precipitation in summer half year

\begin{tabular}{|c|c|c|c|c|c|c|c|c|c|c|c|c|}
\hline \multirow{2}{*}{ 因子 } & \multicolumn{2}{|c|}{ 东南部 } & \multicolumn{2}{|c|}{ 东北部 } & \multicolumn{2}{|c|}{ 中部 } & \multicolumn{2}{|c|}{ 西北部 } & \multicolumn{2}{|c|}{ 北部 } & \multicolumn{2}{|c|}{ 西南部 } \\
\hline & $E$ & $H$ & $E$ & $H$ & $E$ & $H$ & $E$ & $H$ & $E$ & $H$ & $E$ & $H$ \\
\hline 气温 & 0.18 & $-0.46^{*}$ & 0.26 & $-0.58 *$ & 0.33 & $-0.54 *$ & 0.25 & $-0.43^{*}$ & 0.06 & -0.25 & 0.01 & $-0.50^{*}$ \\
\hline 降水 & $0.66^{*}$ & $0.98 *$ & $0.70^{*}$ & $0.98^{*}$ & $0.79^{*}$ & $0.98^{*}$ & 0.22 & $0.99^{*}$ & $0.41^{*}$ & $0.99^{*}$ & -0.02 & $0.80 *$ \\
\hline
\end{tabular}

* 表示通过 0.01 的显著性检验.

\section{3 气候因子异常对长江上游可利用降水量变化的影响}

西太平洋副热带高压 (简称副高)、亚洲季风、高原积雪、赤道太平洋海温以及北半球极浴等气候因子的 年际和年代际振荡必然导致我国夏半年气候的异常变化 ${ }^{[26]}$, 从而引起我国长江上游地区可利用降水量数量 和分布状况的改变. 由于篇幅所限, 本文仅选取了其中的副高、东亚以及南亚季风这三个气候因子, 初步探 讨它们与长江上游夏季可利用降水量的关系.

\section{1 西太平洋副高作用}

文中选取的 5 种副高特征指数分别是由国家气候中心提供的副高面积、强度、脊线位置、北界位置以及 西伸脊点位置. 经统计检验, 长江上游夏季可利用降水量与夏季副高北界、脊线位置变化存在显著相关, 而 且相关系数的区域分布形势基本相同 (图 8); 与副高面积、强度、西伸脊点位置指数之间的相关程度较弱 (图略). 表明当夏季副高脊线或北界位置异常偏西偏北 (偏东偏南) 时, 长江上游东部地区夏季可利用降水 量异常偏少(多). 许多学者分析了西太平洋副热带高压对我国 ${ }^{[27]}$ 、西南地区 ${ }^{[28]}$ 和青藏高原东侧 ${ }^{[29]}$ 等地降 水变化的影响机制. 就西南地区而言, 当副高加强、北进西伸时, 川中、川东位于副高的控制之中; 川西则位 于副高西部偏南暖湿气流输送区, 同时受夏季青藏高原热低压的影响, 西南季风携带的暖湿空气沿副高西 
表 3 夏半年降水量、气温、蒸发量、可利用降水量年代际平均值

Tab. 3 Decade average annual precipitation, temperature, evaporation and utilizable precipitation in summer half year

\begin{tabular}{|c|c|c|c|c|c|c|}
\hline 空间分区 & 因子 & $1960-1969$ 年 & $1970-1979$ 年 & $1980-1989$ 年 & $1990-1999$ 年 & $2000-2008$ 年 \\
\hline \multirow{4}{*}{ 东南部 } & $R$ & 764.30 & 805.40 & 768.78 & 809.95 & 753.11 \\
\hline & $T$ & 22.95 & 22.70 & 22.95 & 22.97 & 23.10 \\
\hline & $E$ & 393.26 & 391.81 & 412.63 & 396.39 & 395.69 \\
\hline & $H$ & 371.19 & 411.95 & 356.16 & 413.57 & 357.42 \\
\hline \multirow[t]{4}{*}{ 东北部 } & $R$ & 691.24 & 657.87 & 809.23 & 619.16 & 730.75 \\
\hline & $T$ & 23.14 & 23.00 & 22.62 & 23.12 & 23.20 \\
\hline & $E$ & 372.97 & 375.01 & 405.76 & 375.82 & 390.37 \\
\hline & $H$ & 318.25 & 281.30 & 412.62 & 244.70 & 338.42 \\
\hline \multirow[t]{4}{*}{ 中部 } & $R$ & 756.40 & 731.55 & 809.38 & 727.85 & 736.23 \\
\hline & $T$ & 25.32 & 25.12 & 24.58 & 25.05 & 25.33 \\
\hline & $E$ & 445.65 & 428.42 & 466.92 & 433.07 & 426.16 \\
\hline & $H$ & 310.75 & 303.14 & 342.46 & 294.78 & 310.07 \\
\hline \multirow[t]{4}{*}{ 西北部 } & $R$ & 546.08 & 499.09 & 538.97 & 548.06 & 545.03 \\
\hline & $T$ & 13.04 & 13.05 & 13.24 & 13.22 & 13.51 \\
\hline & $E$ & 230.02 & 227.68 & 230.64 & 234.03 & 240.18 \\
\hline & $H$ & 321.91 & 284.51 & 323.06 & 323.28 & 314.31 \\
\hline \multirow[t]{4}{*}{ 北部 } & $R$ & 934.47 & 883.15 & 915.07 & 829.16 & 763.68 \\
\hline & $T$ & 20.69 & 20.64 & 20.40 & 20.94 & 21.31 \\
\hline & $E$ & 356.83 & 358.93 & 366.57 & 360.52 & 360.60 \\
\hline & $H$ & 581.35 & 524.22 & 548.51 & 468.65 & 403.08 \\
\hline \multirow[t]{4}{*}{ 西南部 } & $R$ & 723.35 & 717.34 & 761.28 & 757.19 & 708.04 \\
\hline & $T$ & 19.16 & 18.93 & 19.00 & 18.99 & 19.31 \\
\hline & $E$ & 317.18 & 327.29 & 324.24 & 323.08 & 338.65 \\
\hline & $H$ & 402.68 & 390.05 & 393.53 & 434.11 & 372.05 \\
\hline
\end{tabular}

部和青藏热低压之间向北输送, 所以这时有利于川西降水, 而不利于川中、川东降水; 当副高减弱、南退东缩 时, 川中、川东及长江口一带处于暖湿气流输送区, 同时处于副热带锋区和西风带中, 则当西风槽有低槽或 低浴发生移经锋区上空时,则产生不稳定扰动,有利于川中、川东降水;而川西及青藏高原东部常位于高压 控制, 不利于产生降水. 由此可以认为:西太平洋副高偏北(南) 偏西(东), 由此影响川渝地区天气变化, 是 造成长江上游地区降水、气温变化的重要大气环流特征.

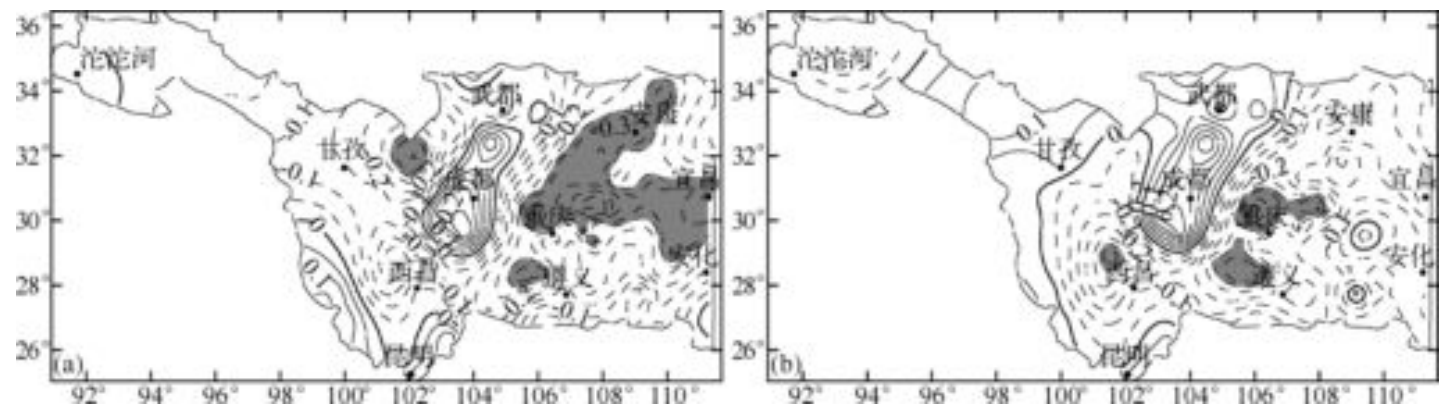

图 8 副高脊线 (a)、副高北界 (b) 和长江上游可利用降水量的相关系数 (阴影区通过 0.05 显著性检验)

Fig. 8 Correlation coefficient of ridge line index of West Pacific Subtropical High(a) , north border index of

West Pacific Subtropical High ( b) with utilizable precipitation in the upper Yangtze River(Areas where correlation coefficients are significant at 0.05 confidence level are shaded) 


\section{2 季风作用}

为了进一步分析长江上游可利用降水量同东亚、南亚夏季风之间的关系, 文中首先引进李建平东亚、南 亚夏季风指数 (来自 www. lasg. ac. cn/staff/ljp/index. html), 进而探讨其间的相关关系. 通过计算长江上游各 站夏季可利用降水量与东亚、南亚夏季风指数的相关系数, 我们发现长江上游地区东部区与东亚夏季风以 及长江上游西北部与南亚夏季风的关系较为密切 (图9), 表明夏季东亚、南亚季风的强弱变化分别对长江上 游东、西部区的夏季可利用降水量有显著影响, 当夏季东亚 (南亚) 季风异常偏强（弱）时, 长江上游东部 (西北部) 的夏季可利用降水量偏少 (多).
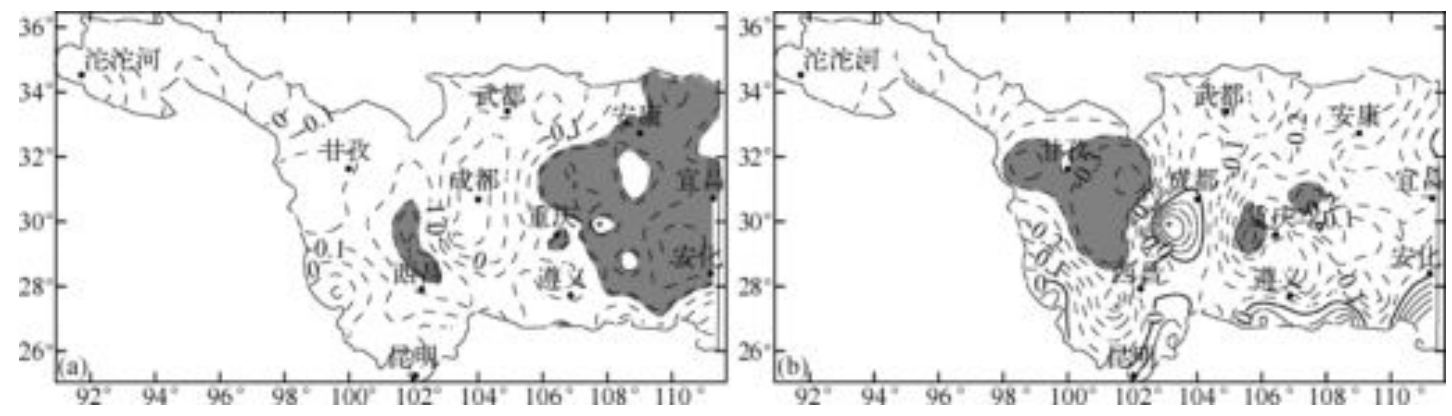

图 9 东亚 (a)、南亚 (b) 夏季风和长江上游可利用降水量的相关系数 (阴影区通过 0.05 显著性检验)

Fig. 9 Correlation coefficient of East(a) and South(b) Asian Summer Monsoon with utilizable precipitation in the upper Yangtze River(Areas where correlation coefficients are significant at 0.05 confidence level are shaded)

总的说来, 长江上游可利用降水量与各气候因子的关系是相当复杂的, 局地特征十分明显, 区域不同则 与之显著相关的气候因子就会有所区别, 这些都充分反映了长江上游地区受若干大气环流系统共同影响且 局地地形复杂的特点. 文献 $[30-31]$ 还分析了青藏高原的热状况、厄尔尼诺事件、西太平洋台风活动等与长 江上游地区气候变化的关系. 所以, 影响长江上游可利用降水量的因素是多方面的, 其他气候因子对长江上 游可利用降水量的影响和作用还有待进一步深人研究.

\section{4 结论与讨论}

(1) 长江上游年平均可利用降水量空间分布的总趋势是随纬度自南向北减少. 四川的峨眉、雅安一带 为长江上游可利用降水量最多的地区. 年平均可利用降水量变化趋势区域差异较大, 东、西部 $\left(103^{\circ} \mathrm{E}\right)$ 可利 用降水量的变化趋势相反, 49 年来东 (西)部总体呈减少 (增加) 趋势.

(2) 长江上游可利用降水量季节变化显著, 可利用降水量主要集中在 5-9 月. 由冬至夏, 可利用降水 量逐渐增多, 8 月达最大值, 川西高原至长江源地区 7 月为全年的最大值;5-9 月出现 2 个或 3 个可利用降 水量大值中心, 其中四川峨眉、雅安一带可利用降水量大值中心稳定少动. 由夏至冬, 可利用降水量逐月减 少, 尤其 10 月以后可利用降水量骤减, 其中以 12 月为最少.

(3) 根据 REOF 分析, 长江上游夏半年可利用降水量的异常空间分布主要有以下几类: 长江上游东南 区、东北区、中部区、西北区、北部区、西南区.

(4) 长江上游夏半年可利用降水量与夏半年气温、降水有这样的对应关系: 当气温偏高、降水量偏少 时, 可利用降水量偏少; 而气温偏低, 降水量偏多时, 可利用降水量偏多. 其中降水量在可利用降水量中起决 定性作用,但因气温变化所造成的影响也不容忽视.

(5) 夏季副高位置的南北变化对长江上游东部地区夏季可利用降水量有显著影响, 当夏季副高脊线或 北界位置异常偏西偏北 (偏东偏南) 时, 该地区可利用降水量异常偏少 (多); 夏季东亚、南亚季风的强弱变 化分别对长江上游东、西部区的夏季可利用降水量有显著影响, 当夏季东亚 (南亚) 季风异常偏强 (弱) 时, 长江上游东部 (西北部) 的夏季可利用降水量偏少 (多).

任国玉等 ${ }^{[31]}$ 认为我国各大流域气温、降水和蒸发变化的原因, 现在还不能给出满意解释. 多数研究认 
为,气温的普遍上升可能与人类活动引起的大气中温室气体浓度增加有关;对降水量的变化,一般认为主要 是海洋和季风系统年代以上尺度的振动引起的, 也有研究认为可能至少部分与人类活动如温室气体排放、 土地利用变化和区域空气污染等因素有关; 我国东部多数流域潜在蒸发量的减少与区域人类活动、特别是 大范围空气污染有关 ${ }^{[32]}$. 文中采用估算蒸发量的经验模型方法得到长江上游地区的可利用降水量, 此方法 在较大范围, 从气候的角度能反映出其宏观分布特征及变化趋势, 由于没有考虑到地形、地貌以及植被等下 垫面条件特征,在精度上与实际存着一定的偏差,这需要我们进行更深人的研究.

\section{5 参考文献}

[ 1 ] 李崇银. 21 世纪的气候变化及其可预报性研究——国际 CLIVER 计划及科学大会介绍. 应用气象学报, 1999, 10 (增刊) : 158-160.

[2] 叶笃正,黄荣辉. 黄河长江流域旱涝规律和成因研究. 济南: 山东科学技术出版社, 1996:11-53.

[ 3 ] 陈 华, 郭生练, 郭海晋等. 汉江流域 1951-2003 年降水气温时空变化趋势分析. 长江流域资源与环境, 2006,15 (3) : $340-345$.

[4] 郝振纯,王加虎,李 丽等.气候变化对黄河源区水资源的影响. 冰川冻土,2006,28(1):1-7.

[ 5 ] 施雅风,姜 殁,苏布达等. 1840 年以来长江大洪水演变与气候变化关系初探. 湖泊科学, 2004,16 (4):289-297.

[ 6 ] 张增信,姜 肜,张金池等. 长江流域水汽收支的时空变化与环流特征. 湖泊科学,2008,20(6):733-740.

[ 7 ] 苏布达,姜 形. 长江流域降水极值时间序列的分布特征. 湖泊科学, 2008, 20(1):123-128.

[ 8 ] 陈家其,施雅风,张 强等. 从长江上游近 500 年历史气候看 $1860 、 1870$ 年大洪水气候变化背景. 湖泊科学, 2006, $18(5): 476-483$.

[ 9 ] Xu CY, Gong LB, Jiang T et al. Decreasing reference evapotranspiration in a warming climate-a case of Changiiang (Yangtze River) catchment during 1970-2000. Advances in Atmospheric Sciences, 2006, 23(4) :513-520.

[10] Zhang Qiang, Xu Chongyu, Stefan Becker et al. Sediment and runoff changes in the Yangtze River basin during past 50 years. Journal of Hydrology, 2006, 331 :511-523.

[11] Zhang Qiang, Tong Jiang, Marco Gemmer et al. Precipitation, temperature and streamflow analysis from 1951 to 2002 in the Yangtze Catchment, China. Hydrological Sciences Journal, 2005, 50(1):65-80.

[12] 马振锋. 高原季风强弱对南亚高压活动的影响. 高原气象, 2003,22(2):143-147.

[13] 李跃清,李崇银. 近四十多年四川盆地降温与热带西太平洋海温异常的关系. 气候与环境研究, 1999, 4 (4): 388-399.

[14] Easterling DR, Peterson TC, Karl TR. On the development and use of homogenized climate data sets. J Climate, 1996, 9:1429-1434.

[15] Takahashi Hiroichiro. The calculation method of monthly average temperature, precipitation and evaporation. Synoptic, $1979,26(12): 759-763$.

[16] 陶 云,赵 荻,何 华等. 云南省大气中水资源分布特征初探. 应用气象学报,2007,18(4):506-515.

[17］周长艳,李跃清,彭 俊. 高原东侧川渝盆地降水与水资源特征及变化. 大气科学,2006,30 (6): 1217-1226.

[18］李 林,李风霞,郭安红等. 近 43 年来“三江源”地区气候变化趋势及其突变研究. 自然资源学报, 2006,21 (1): 79-85.

[19］李永华,毛文书,高阳华等. 重庆区域旱涝指标及其变化特征分析.气象科学,2006,26(6):638-644.

[20］吴洪宝,吴 蕾.气候变率诊断和预测方法. 北京:气象出版社, 2005:15-44.

[21] 施 能,陈家其,屠其璞. 中国近 100 年来 4 个年代际的气候变化特征. 气象学报, 1995,53(4):431-439.

[22] 杜川利,刘晓东. 中国区域陆地水资源数值模拟分析.气象, 2009,35(8): 49-60.

[23] North GR, Thomas LB, RF Cahalan. Sampling errors in the estimation of empirical orthogonal functions. Mon Wea Rev, $1982,110: 699-706$.

[24] 赵宗慈, 王绍武, 罗 勇. IPCC 成立以来对温度升高的评估与预估. 气候变化研究进展, 2007,3(3): 183-184.

[25] 林学椿, 于淑秋,唐国利. 中国近百年温度序列. 大气科学, 1995, 19(5):525-534.

[25] 宋正山,杨 辉,张庆云. 华北地区水资源各分量的时空变化特征. 高原气象,1999,18(4) :552-566.

[26] 吴统文,钱正安. 青藏高原冬春积雪异常与中国东部地区夏季降水关系的进一步分析. 气象学报, 2000,58 (5) :570-581.

[27］陶诗言,卫 捷.再论夏季西太平洋副热带高压的西伸北跳. 应用气象学报,2006,17(5):513-525.

２8］唐佑民,翟武全,许金洪. 我国西南地区夏季降水异常与太平洋海温季节演变的关系. 海洋与湖沼, 1997, 28 (1) :88-95.

[29］李跃清,李崇银. 青藏高原东侧地区夏季气温变化及其可能成因. 高原气象,2003,22 (增刊) : 25-31.

[30] 徐裕华. 西南气候. 北京:气象出版社, 1991:32-46.

[31] 胡豪然,毛晓亮,梁 玲. 近 50 年四川盆地汛期极端降水事件的时空演变. 地理学报, 2009,64(3): 278-288.

[32] 任国玉,姜 殁,李维京等.气候变化对中国水资源情势影响综合分析. 水科学进展, 2008, 19(6): 772-779.

[33] 赵宗慈,王绍武,徐 影等. 近百年我国地表气温趋势变化的可能原因. 气候与环境研究,2005, 10 (4):808-817. 